\title{
Prospective study of clinical, laboratory, and ancillary staff with accidental exposures to blood or body fluids from patients infected with HIV
}

\author{
MARIAN MCEVOY, KHOLOUD PORTER, PHILIP MORTIMER, NORMAN SIMMONS, \\ DAVID SHANSON
}

\begin{abstract}
In a prospective study of $\mathbf{1 5 0}$ health care workers in the United Kingdom who had been accidentally exposed to the human immunodeficiency virus no evidence of transmission was found. Larger studies in the United States and anecdotal accounts in publications from other countries confirm that the risk of occupational infection is very low. Health care workers must adopt safe procedures at all times, however, to avoid exposure to infection.
\end{abstract}

\section{Introduction}

The first case of the acquired immune deficiency syndrome (AIDS) in the United Kingdom was documented in late 1981,' and during the next year surveillance of the condition was begun at the Public Health Laboratory Service Communicable Disease Surveillance Centre in collaboration with the Communicable Disease (Scotland) Unit. The number of reports of AIDS grew, and by September 1984 the cases of 81 patients, 36 of whom had died, were known (PHLS, unpublished). At that time seroconversion in a nurse who sustained a needlestick injury while caring for a patient with AIDS was reported. ${ }^{2}$ Although it was impossible to estimate accurately the size of the groups at risk of becoming infected, it was believed that the number of people who were capable of transmitting infection was much greater than the number of cases. Many of these people would present for investigation and treatment to health care workers, who would probably be at risk of accidental exposure, leading to further possible seroconversions. Therefore, it was decided that in collaboration with the Association of Medical Microbiologists the surveillance scheme for AIDS at the Communicable Disease Surveillance Centre would be extended to include collecting reports of accidental injuries in which health care workers were exposed to the blood or body fluids of patients who were infected with the human immunodeficiency virus (HIV).

PHLS Communicable Disease Surveillance Centre, 61 Colindale Avenue, London NW9 5EQ

MARIAN MCEVOY, MB, MFCM, consultant epidemiologist

KHOLOUD PORTER, BSC, statistical assistant

\section{PHLS Virus Refèrence Library}

PHILIP MORTIMER, MD, FRCPATH, consultant virologist

Association of Medical Microbiologists Safety Committee

NORMAN SIMMONS, MB, FRCPATH, consultant microbiologist, Guy's Hospital

DAVID SHANSON, MB, FRCPATH, consultant microbiologist, St Stephen's Hospital

Correspondence to: Dr McEvoy.
The aim of our study was to search for evidence of transmission of HIV to health care workers by occupational exposure. The objectives were: $(i)$ to identify health care workers who seroconverted to HIV by serological testing as soon as possible after exposure and thereafter at intervals of three and 12 months and (ii) to record the appearance of opportunist diseases which fulfilled the criteria for the case definition of AIDS in those who seroconverted.

\section{Method}

The original definition of AIDS that had been compiled by the Centers for Disease Control in Atlanta, Georgia, and the,amended definition compiled in 1985 were used ${ }^{3+}$ For the study people in the following categories were considered capable of transmitting infection: (i) people with AIDS and (ii) symptomatic or asymptomatic people whose infection was confirmed by the results of laboratory tests.

Injuries sustained during the care of people who were thought capable of transmitting infection were considered to be exposures: needlestick or other sharp injuries, splashes to mucous membranes or broken skin, inhalation of aerosols, injuries sustained during postmortem examinations, and any other injuries which the consultant microbiologist acting as safety officer considered to be a risk to the health of the injured person.

Health care workers were considered to be cases of occupationally acquired infection if there were no identifiable risk factors for the development of infection, if antibody to HIV was not detected in their serum immediately after occupational exposure but was detected three or more months after exposure, and if they had no other relevant exposures in the interim period.

Reports of exposures were made in strict confidence, and with the permission of the health worker concerned, by telephone or letter from the reporting doctor, or deputy to the director, or consultant epidemiologist responsible for the study at the centre, or through the safety committee of the Association of Medical Microbiologists. After a report was received postal questionnaires were used to collect basic epidemiological data, information about the exposure, and details of the patient to whose secretions the health care worker was exposed. Although the names of the health care workers were sometimes provided, they were not requested, and a phonetic alphanumeric code was provided to protect identity, which ensured the elimination of duplicate reports. The questionnaire was completed by the reporting medical officer or deputy, who requested laboratory examination of samples of serum as soon as possible after exposure and then at intervals of three and 12 months. Serological testing was performed either locally or at the Public Health Laboratory Service Virus Reference Laboratory. It was arranged that if seroconversion had occurred a standard epidemiological interview would be carried out to eliminate other risk factors.

\section{Results}

Between 1 January and 31 December 1986, 150 exposures were reported. Altogether, $95(63 \%)$ of these occurred in hospitals in the four Thames health regions. Exposures were reported in 41 male and 109 female health care workers. The men were aged 22 to 58 years, median 31 years; the 
women were aged 19 to 56 years, median 28 years. There were $91(61 \%)$ nurses, $32(21 \%)$ doctors, eight (5\%) laboratory workers, and $19(13 \%)$ others, such as physiotherapists, radiographers, occupational therapists, porters, and other ancillary staff. The table lists the types of injuries according to occupational group. There were 76 needlestick and other injuries from sharp instruments, 60 of which were sustained by nurses and doctors. In $101(67 \%)$ of the 150 injuries there was exposure to blood and in $24(16 \%)$ to urine. The remainder of the injuries were mostly from splashes and aerosol inhalations of saliva, vomitus, faeces, pus, ascitic fluid, and sweat. A surgeon stabbed himself with a spicule of bone during an operation, a nurse pricked herself with a trochar used to drain peritoneal fluid, and another nurse pricked herself with a scalpel which had been used to incise an abscess. One nurse gave mouth to mouth resuscitation, and two others who helped were splashed with saliva. One nurse was bitten by an infected person.

Types of accidental exposure by occupational group

\begin{tabular}{lccccc}
\hline & $\begin{array}{c}\text { Nurse } \\
(\mathbf{n}=91)\end{array}$ & $\begin{array}{c}\text { Doctor } \\
(\mathbf{n}=32)\end{array}$ & $\begin{array}{c}\text { Laboratory } \\
\text { worker } \\
(\mathbf{n}=8)\end{array}$ & $\begin{array}{c}\text { Other } \\
(\mathbf{n}=19)\end{array}$ & $\begin{array}{c}\text { Total } \\
(\mathbf{n}=150)\end{array}$ \\
\hline Needlestick & 28 & 14 & 2 & 9 & 53 \\
Other sharp instrument & 11 & 7 & 0 & 5 & 23 \\
Splashes & 18 & 6 & 0 & 0 & 24 \\
Aerosols & 0 & 0 & 2 & 3 & 5 \\
Other & 34 & 5 & $4^{\star}$ & 2 & 45 \\
\hline
\end{tabular}

* Two did not usually work in the laboratory, but this is where the exposure occurred.

The patients to whose secretions the health care workers were exposed were: 56 with AIDS fulfilling the criteria for case definition, including 50 homosexuals, four intravenous drug abusers, and two patients with transfusion associated AIDS; 88 seropositive people with symptoms which did not yet fulfil the criteria for case definition; three with haemophilia and three intravenous drug users whose serological state was not confirmed at the time of reporting but who had symptoms of HIV infection. Altogether, 109 health care workers were followed up for more than one year and 41 for between one and 12 months, median nine months. No seroconversions were observed in the 150 health care workers.

\section{Discussion}

It is encouraging that no seroconversions were found in the health care workers, even though the group was small. There was a preponderance of women (73\%) and they were slightly younger than the men, but this may be explained by accidental exposures occurring in student nurses in the group. The $123(82 \%)$ exposures to nurses and doctors took place during patient care. It is interesting that only $32(21 \%)$ exposures were reported in doctors compared with $91(61 \%)$ in nurses. Junior doctors may be more aware of the routes of transmission of HIV and therefore more cautious than nurses, or they may be more reluctant to report accidental injuries to themselves. Two thirds of the exposures were reported from hospitals in the four Thames regions: throughout the outbreak of AIDS in the UK up to three quarters of cases have consistently been reported from London hospitals.

In the United States McCray reported 938 accidental exposures

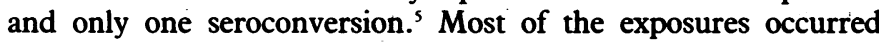
during patient care, ${ }^{5}$ but he also described 373 exposures that were similar to the $76(51 \%)$ needlestick and sharp instrument injuries in our study which he considered to be preventable. Both studies suggest that recapping needles is a dangerous practice which is likely to put health care workers at risk of exposure.

The chances of developing infection with HIV from a single, accidental exposure are probably less than $1 \%$ and much less than that of developing hepatitis $B$ infection from a similar type of injury. ${ }^{6}$ Indeed, a health care worker contracted hepatitis $B$ infection after a needlestick injury sustained during a transbronchial biopsy on a patient with AIDS but had no evidence of infection with HIV 15 months later. ${ }^{7}$

Although health care workers throughout the world have undoubtedly been exposed to HIV infection thousands of times, only seven cases of occupationally acquired infection in which seroconversion occurred as a result of exposure have been documented: a female nurse in the UK sustained an "inoculation" type of needlestick injury ${ }^{2}$; a female nurse in the USA received a deep intramuscular needlestick injury ${ }^{8}$; a female nurse from Martinique sustained a needlestick injury without injection of blood'; and a female nurse from France sustained a superficial needlestick injury during a thoracentesis. ${ }^{10}$ Three women health care workers received splashes of infected blood to skin which was not covered and thought not to be intact, and one of the three also received a splash to oral mucous membranes (reported by Centers for Disease Control, Atlanta, 22 May 1987). All seven workers were exposed to blood contaminated with HIV and none had other risk factors to explain how they might otherwise have become infected.

There have also been several reports of seropositive health care workers who were probably exposed to the blood or body fluids of patients with AIDS but who were not shown to seroconvert as a result of exposure: a female surgeon from Denmark who had worked in Kinshasa and had had multiple exposures to blood died with AIDS in $1977^{11}$; a male hospital worker from the USA who sustained an injury from a needle used on an unknown patient and who did not appear to have other risk factors died with AIDS $^{12}$; a female health care worker in the USA sustained two needlestick injuries from patients with AIDS, had no apparent risk factors, and was subsequently found to be seropositive from $\mathrm{HIV}^{13}$; and a male laboratory worker from the USA who had received several injuries with sharp instruments with possible exposure to infected blood was found to be seropositive. ${ }^{13}$ One of a group of 1200 dental care workers who worked in the United States probably acquired HIV infection by occupational exposure ( $\mathrm{R} S$ Klein, paper presented at III International Conference of AIDS, Washington, 1987.) Unfortunately, baseline sera were not available for any of these people. There is also a small group of people who were not health care workers but who might be considered to have had "accidental" domestic exposures: the sibling of an infected boy in Dominica developed antibodies to $\mathrm{HIV}$ after being given vitamin injections at home with the same inadequately sterilised syringe and needle used for his seropositive brother ${ }^{14}$; the mother of an infected child who had frequent contact with the blood and other body fluids of her son but who did not recall specific needlestick injuries seroconverted to HIV $^{15}$; the brother of a boy who died with AIDS was seropositive and is thought to have been bitten by his infected sibling ${ }^{16}$; a British woman who had provided home nursing care to a man with AIDS and who had skin lesions on her hands subsequently developed opportunist infections and died with AIDS (M McEvoy, P Grint, $M$ Rademaker, paper presented at III international conference on AIDS, Washington, 1987). In none of these cases were there other apparent risk factors, but the two women had had extensive unprotected exposure to infected blood and body fluids. In the case of the British woman, particularly, there was no knowledge or opportunity for prevention of cross infection, and the kind of exposure was much different from that which might occur in a hospital with adequate facilities and a staff trained in safe nursing techniques.

Guidelines for health care workers have been produced in various countries. ${ }^{617-22}$ Those provided by the Department of Health and Social Security emphasise that simple measures such as good hygiene and safe disposal of infected sharp instruments and waste will provide protection. ${ }^{22}$ Although national public health campaigns have been instituted, it is likely that the seroprevalence in some groups of people will remain high for many years. It is impossible to know whether patients who present with what might be, or seem to be, unrelated illnesses are infected with HIV and capable of transmitting infection. Therefore, it would be sensible for all health care workers not only to follow guidelines for the management of known infected patients but to be vigilant in standards of hygiene and safety while carrying out routine procedures.

The study would not have been possible without the cooperation of all reporting microbiologists and clinicians and their deputies. We thank them for their support and to continue the study they are asked to report 
occupational exposures, wherever possible, by letter or telephone to the PHLS Communicable Disease Surveillance Centre, 61 Colindale Avenue, London NW9 5EQ. Tel: 01-200 6868.

\section{References}

1 Dubois RM, Braithwaite MA, Mikhail JR, et al. Primary pneumocystis carinii and cytomegalovirus infections. Lancet $1981 ;$ ii: 1339.

2 Anonymous. Needlestick transmission of HTLV-III from a patient infected in Africa [Editorial]. Lancet 1984;ii:1376-7.

3 Anonymous. CDC update on acquired immune deficiency syndrome (AIDS)—United States. $M M W R$ 1982;31.

4 Anonymous. CDC revision of the case definition of AIDS for national reporting-United States. $M M W R$ 1985;34:373-6.

5 McCray E. The Co-operative Needlestick Surveillance Group. Occupational risk of the acquired immune deficiency syndrome among health care workers. $N$ Engl f Med 1986;314:1127-32.

6 Anonymous. CDC guidelines for the prevention of transmission of infection with HTLV-III/LAV in the workplace. $M M W R$ 1986;35.

7 Gerberding JL, Hopewell PC, Kanninsky LS, Sande M. Transmission of hepatitis B without transmission of AIDS by accidental needlestick. $N$ Engl f Med 1985;312:56-7.

8 Stricof RL, Morse DL. HTLV-III/LAV seroconversion following a deep intramuscular needlestick injury. $N$ Engl f Med 1986;314:1115.

9 Neisson-Vernant C, Arfi S, Mathez D, Leibowitch J Monplaisir N. Needlestick HIV seroconversion in a nurse. Lancet 1986;ii:814.
10 Oksenhendler E, Harzic M, Le Roux IM. HIV infection with seroconversion after a superficial needlestick injury to the finger. $N$ Engl $\mathcal{F}$ Med 1986;315:582.

11 Bygbjerg IC. AIDS in a Danish surgeon (Zaire, 1976). Lancet 1983;i:925.

12 Belani A, Dunning R, Dutta D, et al. AIDS in a hospital worker. Lancet 1984;i:676.

3 Anonymous. CDC update: evaluation of HTLV-III associated infection in health care personnel -United States. MMWR 1985;34:575-8.

14 Koenig RE, Gautier T, Levy JA. Unusual intrafamilial transmission of human immunodeficiency virus. Lancet 1986;ii:627.

15 Anonymous. CDC: apparent transmission of HTLV-III/LAV from a child to a mother providing health care. $M M W R$ 1986;35:76-9.

16 Wahn V, Kramer H, Voit T, Brüster HT, Scrampical B, Scheid A. Horizontal transmission of HIV infection between two siblings. Lancet 1986;ii:694.

17 Advisory. Committee on Dangerous Pathogens. Acquired immune deficiency syndrome (AIDS)interim guidelines. London: Department of Health and Social Security, December 1984.

18 Department of Health and Social Security. Acquired immune deficiency syndrome. General information for doctors. Booklet $l$. London: DHSS, May 1985.

19 Department of Health and Social Security. Information for doctors concerming the introduction of the HTLV-III antibody test. Booklet 2. London: DHSS, October 1985.

20 Department of Health and Social Security. Guidance for surgeons, anaesthetists, dentists and their teams in dealing with patients infected with HTLV-III. Booklet 3. London: DHSS, April 1986.

21 Department of Health and Social Security. Acquired immune deficiency syndrome (AIDS) and artificial insemination. Guidance for doctors at clinics. Booklet 4. London: DHSS, July 1986.

22 Advisory Committee on Dangerous Pathogens. LAVIHTLV-III - the causative agent of AIDSand related conditions. Revised guidelines. London: DHSS, June 1986.

(Accepted 15 May 1987)

\section{Abstract}

The "malpractice crisis" in the United States cannot be understood in isolation. Litigation is precipitated by features of the American health care and social security systems. Relative to the United Kingdom, there are fewer barriers of access to the courts, although the role of contingency fees has probably been exaggerated. Given the great institutional differences between the UK and the USA, the crisis seems unlikely to be replicated here unless there are further moves towards privatising both the costs of providing health care and the costs of its failures.

It is concluded that a marginal change in the frequency or average cost of claims could have a serious impact on National Health Service resources, the medical defence societies, recruitment to specialties, and clinical practice. Debate over possible reforms is compromised by the dearth of good empirical data. Any changes, however, must address both the deterrence of bad practice and the compensation of injured patients.

Centre for Socio-Legal Studies, Wolfson College, Oxford OX2 6UD

LOIS QUAM, BA, research assistant

PAUL FENN, BA, BPHIL, senior research officer

ROBERT DINGWALL, MA, PHD, senior research officer

Correspondence to: Dr Dingwall.

\section{Introduction}

A previous paper (13 June 1987, p 1529) analysed the nature of the "malpractice crisis" in American medicine and argued that this could not be understood in isolation from other social and economic changes in health care delivery in the USA. This second paper develops that analysis to ask whether the UK is experiencing or might experience the same crisis and discusses both those factors in the health care system that may precipitate claims and those in the legal system that influence their outcomes.

\section{The health care system}

The differences between the National Health Service and American health services are gross and well recognised. ${ }^{1}$ The close relation between the cash nexus of private practice and high rates of litigation in the USA is less clearly understood.

Patients who have paid directly for their care, through a mixture of insurance premiums and contributions out of pocket, seem more likely to feel aggrieved when treatment fails. ${ }^{2}{ }^{3}$ Moreover, litigation is fuelled by the sheer cost of extra care after an iatrogenic injury or treatment ${ }^{+5}$ Along with the immediate expense a permanently disabled patient may face continuing difficulty in obtaining insurance coverage or have to pay excess premiums. Private health insurance, or membership in a prepaid health maintenance organisation, is normally available only after a medical examination, unless offered through a workplace scheme, which requires sufficient health to hold stable employment. The only alternatives are the restrictive government schemes, Medicare and Medicaid. Thus, for example, awards are so large in alleged "brain damaged" baby cases because the sum must be sufficient to cover all relevant medical and nursing care for the child's expected lifetime.

The division of labour in medicine also seems to be implicated in the 